\title{
A leve med diabetes type 1 er en balansekunst
}

Personer med diabetes type 1 må planlegge godt og ta mange hensyn. Sykepleiere kan lære mye av erfaringene deres.

\section{Tone Singstad}

Spesialsykepleier

Endokrinologisk avdeling, Akershus universitetssykehus

Diabetes

Behandling

Sykepleien 2022;110(87856):e-87856

DOI: $10.4220 /$ Sykepleiens.2022.87856

\section{Hovedbudskap}

Artikkelen gir en faglig gjennomgang av elementær kunnskap ved diabetes type 1. Sykdommen kjennetegnes av insulinmangel. For å behandle pasientgruppen er det nødvendig å forstå hvordan insulin virker, og hva som påvirker insulinets effekt.

Diabetes type 1 er en kronisk sykdom som utvikles over år, men som debuterer akutt eller subakutt (1). Det er som oftest yngre mennesker under 40 år som rammes, men sykdommen kan ramme i alle aldre. Sykdommen skyldes en autoimmun reaksjon mot betacellene i bukspyttkjertelen som medfører at insulinproduksjonen etter hvert stopper opp (2).

Hormonet insulin er vesentlig for at energiomsetningen i kroppen skal fungere. Uten insulin forblir glukosen i blodet og viderefordeles ikke til cellene. Blodsukkeret stiger som et resultat av dette, og cellene får ikke tilgang til nødvendig energi. 
For å behandle og veilede en person med diabetes type 1 er det avgjørende at vi forstår hvordan insulinet fungerer i kroppen, og hva som påvirker insulinbehovet (1).

Historisk har behandling med insulin bare vært tilgjengelig i 100 år. Den første gutten som fikk insulin injisert, var 14 år gamle Leonard Thompson fra Canada. Det skjedde i 1922 (2).

Den gangen ble insulin laget av bukspyttkjertler fra gris, og det måtte omtrent 70 bukspyttkjertler til for å behandle én person med diabetes i ett år. I dag produseres insulin kunstig og har ingenting med gris å gjøre.

\section{Behovet for insulin varierer}

Det er store individuelle forskjeller i behovet for insulin. Det er ikke mulig å avgjøre hvor mye insulin en person trenger, uten å prøve seg litt frem. Prinsippene for insulinbehandling er gjenkjennelige og viktige å ha med seg i behandlingen av personer med diabetes (figur 1).

Figur 1. Prinsipper for insulinbehov

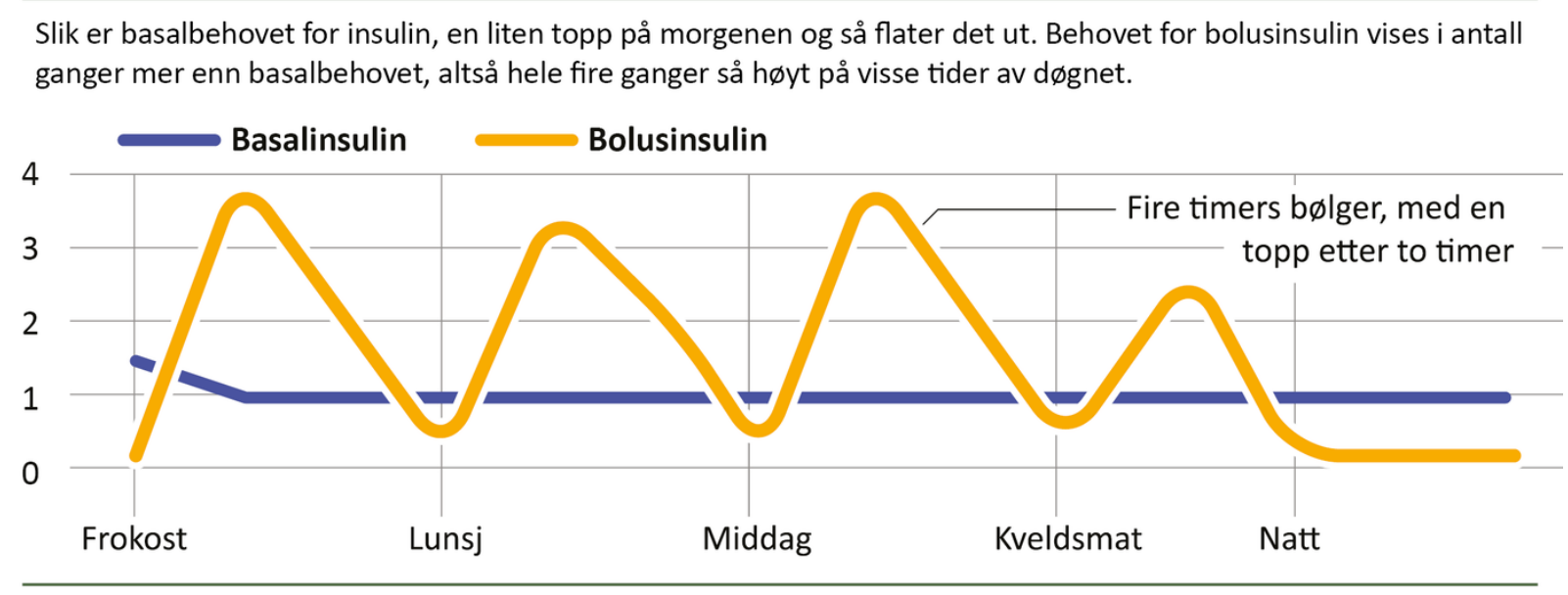

Alle mennesker har et basalbehov for insulin. Det vil si at behovet nesten aldri er fraværende. Som en respons på inntak av mat vil det tydelig komme frem et mangedoblet behov for insulin, som ofte betegnes som bolusdose.

Responsen henger sammen med matens innhold av karbohydrater, men også med andre energikilder i maten som omdannes til glukose når maten har passert fordøyelsen. Dersom personen ikke har diabetes, vil betacellene tilpasse produksjonen av insulin (2) til behovet.

Stiger nivået av glukose i blodet, stiger produksjonen av insulin. Dersom nivået av glukose i blodet synker, reduseres produksjonen av insulin. På den måten oppnås en god utnyttelse av glukose til cellene, og resultatet blir et stabilt blodsukker. 


\section{«Både mangel på insulin og overdosering av insulin kan få fatale konsekvenser.»}

Derfor er det viktig for en person med diabetes å ha passe mengde insulin $\mathrm{i}$ kroppen for å holde blodsukkeret så stabilt som mulig. Når den som har diabetes, ikke lenger klarer å ivareta denne oppgaven, må helsepersonell ta over og gjøre jobben.

Mange med diabetes føler seg ikke trygge på at helsepersonell kan dette. Både mangel på insulin og overdosering av insulin kan få fatale konsekvenser.

\section{Verktøy helsepersonell bør kjenne til}

En person med diabetes type 1 får mye kunnskap om og erfaringer med det å leve med diabetes. De må lære mye i starten. Det er vanlig at pasienter i Norge enten er innlagt på sykehus den første tiden, eller får tett oppfølging av en spesialist på diabetes ved en poliklinikk på sykehus.

Alle med diabetes type 1 får tilbud om oppfølging for sykdommen sin i spesialisthelsetjenesten. Egenbehandling av sykdommen står sterkt, men det er anbefalt at helsepersonellet kjenner til noen verktøy.

\section{Insulinbehandling}

I dag er det to hovedstrategier for å behandle denne pasientgruppen med insulin (4).

1. Mangeinjeksjonsbehandling med insulinpenner

Denne behandlingsstrategien bygges i hovedtrekk opp med to ulike insulintyper: en insulintype som dekker basalbehovet for insulin, og en insulintype som skal dekke behovet for bolusdoser med insulin. Basalbehovet for insulin dekkes av langsomtvirkende insulin som injiseres en til to ganger per døgn.

For å dekke behovet for insulin til måltider og når det trengs å justeres, får pasienten bolusdoser med hurtigvirkende insulin, der dosene tilpasses etter hva som skal spises, og etter glukosenivået som måles.

2. Insulinbehandling med insulinpumpe 
En insulinpumpe inneholder kun hurtigvirkende insulin. Mest brukt er hurtigvirkende insulindialog, som er et mer moderne insulin med raskere innsettende effekt og varighet på cirka fire timer. Insulinpumpen må derfor være koplet hele døgnet til den som har diabetes type 1, slik at tilførselen av insulin ivaretas.

Behandling med insulinpumpe gir en kontinuerlig basaldose som subkutan infusjon hele døgnet. Basaldoseringen kan stoppes midlertidig eller justeres dersom det er behov for det.

Bolusdoser med insulin gis også ved måltider eller i situasjoner der det er behov for ekstra insulin. Noen moderne insulinpumper kan tilpasse noe av insulindoseringen på bakgrunn av glukoseverdier som monitoreres kontinuerlig med en tilhørende sensor.

Dersom insulinpumpen ikke fungerer, er det fullt mulig å konvertere til mangeinjeksjonsbehandling. Da må basaldosering i pumpen erstattes med langsomtvirkende insulin i penn.

Bolusdosene med hurtigvirkende insulin i penn kan gis i samme dosering som en bolusdose satt med insulinpumpen. Tabell 1 viser insulin og virketider. 
Tabell 1. Insulin og virketider

\begin{tabular}{|c|c|c|c|c|}
\hline Type insulin (ATC-kode) & Virkestoff & ATC-kode & $\begin{array}{l}\text { Innsettende effekt / } \\
\text { maks effekt* }\end{array}$ & $\begin{array}{l}\text { Virkningsvarighet } \\
\text { (etter prepara- } \\
\text { tomtalen) }\end{array}$ \\
\hline \multirow[t]{3}{*}{$\begin{array}{l}\text { Hurtigvirkende } \\
\text { insulinanalog** - A10AB }\end{array}$} & Insulin glulisin & IA10AB06 & $\begin{array}{l}10-20 \min / 0,5-2 \\
\text { timer }\end{array}$ & 3-5 timer \\
\hline & Insulin lispro & A10AB06 & $\begin{array}{l}10-20 \mathrm{~min} / 0,5-2 \\
\text { timer }\end{array}$ & 3-5 timer \\
\hline & Insulin aspart & A10AB04 & $\begin{array}{l}10-20 \mathrm{~min} / 0,5-2 \\
\text { timer }\end{array}$ & 3-5 timer \\
\hline $\begin{array}{l}\text { Hurtigvirkende humant insu- } \\
\text { lin - A10AB01 }\end{array}$ & Insulin (humant) & A10AB01 & 0,5 timer / 1-3 timer & 7-9 timer \\
\hline $\begin{array}{l}\text { Middels langtidsvirkende } \\
\text { insulin (humant, } \mathrm{NPH}^{* * *} \text { ) - } \\
\text { A10AC }\end{array}$ & Insulin (humant) & A10AC01 & & \\
\hline \multirow[t]{4}{*}{$\begin{array}{l}\text { Langtidsvirkende insuli- } \\
\text { nanalog - A10AE }\end{array}$} & Insulin glargin & A10AE04 & $* * * *$ & $\begin{array}{l}\text { 16-36 timer- } \\
\text { varierer mellom } \\
\text { de ulike prepara- } \\
\text { tene }\end{array}$ \\
\hline & $\begin{array}{l}\text { Insulin glargin } \\
\text { (biosimilar) }\end{array}$ & A10AE04 & $* * * *$ & 16-24 timer \\
\hline & Insulin detemir & A10AE05 & $* * * *$ & opptil 24 timer \\
\hline & Insulin degludec & A10AE06 & $* * * *$ & opptil 48 timer \\
\hline $\begin{array}{l}\text { Blanding av hurtigvirkende } \\
\text { og middels langtidsvirkende } \\
\text { insulinanalog - A10AD }\end{array}$ & $\begin{array}{l}\text { Insulin lispro } \\
\text { Insulin aspart }\end{array}$ & $\begin{array}{l}\text { A10AD04 } \\
\text { A10AD05 }\end{array}$ & $\begin{array}{l}10-20 \mathrm{~min} / 1-4 \\
\text { timer }\end{array}$ & Inntil 20 timer \\
\hline \multicolumn{5}{|c|}{$\begin{array}{l}\text { *De angitte tidene er gjennomsnittstall. Virkningstiden avhenger av en rekke faktorer som injeksjonssted, muskelaktivitet ved injeksjonsste- } \\
\text { det, temperatur osv. og kan variere med } 25-30 \text { prosent hos samme pasient fra dag til dag, og } 50 \text { prosent fra pasient til pasient. } \\
* * \text { Insulin i oppløsning kan gis subkutant, intramuskulært og intravenøst. } \\
* * * \text { Nøytralt protamin Hagedorn-insulin } \\
\text { ****Preparatene har lengre virketid enn NPH-insulin og mindre uttalt virkningsmaksimum. Virketiden er doseavhengig og viser betydelig } \\
\text { intra- og interindividuell variasjon. } \\
\text { Kilde: Helsedirektoratet. Tabell fra retningslinjene om insulin og virketider (4). }\end{array}$} \\
\hline
\end{tabular}

\section{Blodsukkermåling og glukosemonitorering}

Adekvat insulinbehandling innebærer at personer med diabetes type 1 og de som skal behandle personene med denne sykdommen, har god oversikt over blodsukkeret eller glukosenivået i blodet.

\section{«Det er sammenheng mellom god glukosekontroll og lavere risiko for å utvikle alvorlige komplikasjoner.»}

Blodsukkeret måles for å få oversikt over og justere behandlingen samt oppnå et nivå som er mest mulig innenfor normalområdet. Det er vanlig å angi målområdet for glukose mellom $4 \mathrm{mmol} / \mathrm{l}$ og $10 \mathrm{mmol} / \mathrm{l}$, slik at blodglukosen holdes innenfor dette området minst 70 prosent av tiden. Vi vet at det er sammenheng mellom god glukosekontroll og lavere risiko for å utvikle alvorlige komplikasjoner av diabetes (4).

I dag har vi to metoder for å overvåke nivået av glukose i blodet: 
Mange forskjellige apparater er tilgjengelig på markedet, men prinsippene for håndtering og bruk er like. Du må ha ren finger der du perforerer huden med et lite stikk. Bloddråpen påføres en strimmel som står i blodsukkerapparatet, og resultatet dukker raskt opp på en skjerm.

Vanlige feilkilder er at pasienten ikke har rene fingre, og at «falskt sukker» gir for høy verdi. Håndsprit eller desinfeksjonst $\varnothing$ rk er ikke egnet å bruke før blodsukkermåling da disse er basert på alkohol, som igjen er laget av sukker.

2. Kontinuerlig vevsglukosemåling (CGM - Continuous Glucose Monitoring, eller sensor)

Flere med diabetes type 1 har dette behandlingshjelpemiddelet, som gir en kontinuerlig oversikt over glukosenivået i kroppen. Dette er et godt hjelpemiddel som har hjulpet mange til bedre å forstå sitt eget behov for insulin.

I tillegg til at vi får informasjon om glukosenivået, får vi også informasjon om hvilken retning glukosenivået er på vei. Trendpiler indikerer hvor raskt glukosenivået endres, og hvorvidt det er stigende eller fallende. Denne informasjonen er nyttig når man skal tilpasse insulindoser.

Vanlige feilkilder er at sensorene utsettes for trykk, og at verdiene blir feil. Dersom personen som har sensor, har underskudd av væske i kroppen, gir også sensorene for lave verdier. Det er også kjent at noen medikamenter kan påvirke verdiene som sensorene registrerer (5).

\section{Hvordan beregnes bolusdose med insulin?}

Diabetes type 1 er ikke en matsykdom. Toleransen for sukker og karbohydrater er god. For mange er diabetessykdommen et vanskelig tema. Pasientgruppen blir ofte utsatt for bedrevitere som mener noe om hva som er bra å spise eller ikke spise når man har diabetes.

For å balansere blodsukkeret og ha tilstrekkelig med insulin vil en person med diabetes type 1 alltid trenge en bolusdose ved inntak av mer enn 10 til 20 gram karbohydrater. Det å kunne beregne omtrentlig mengde karbohydrater i et måltid kan for mange være til god hjelp for å få rett dosering av bolusdose til måltid (7). Se gjerne e-læring om temaet (8).

I denne sammenhengen er det også naturlig å snakke om korreksjonsdoser. En bolusdose består både av det insulinet som skal til for å dekke inntaket av karbohydrater, samt er en korreksjon av eventuelt for høy blodglukose. 
Glukosenivået i blodet vil altså avgjøre om det er behov for ytterligere dosering av insulin i tillegg til behovet som maten fører til. En korreksjonsdose er enda en dose insulin som tas dersom dosen som er beregnet til å dekke maten man skal spise, ikke er tilstrekkelig.

\section{Andre faktorer kan påvirke insulinbehovet Infeksjon og annen sykdom}

Det er ofte ved annen sykdom at personer med diabetes får ekstra utfordringer med å holde kontroll på blodsukkeret. Det er vanlig å beregne at feber $\varnothing$ ker insulinbehovet med 25 prosent ved hver grad over $37,5^{\circ} \mathrm{C}$.

Ved steroidbehandling er det viktig å kjenne til at behandling med ulike steroider gir $\varnothing \mathrm{kt}$ insulinbehov. Mange får ikke nok insulin ved denne typen behandling.

Behandlingsveilederen innen endokrinologi gir en utvidet beskrivelse av hvordan dette kan håndteres (9), men som et utgangspunkt kan man kjenne til at kortikosteroider $\varnothing$ ker basalinsulinbehovet med 30 til 100 prosent.

\section{Fysisk aktivitet og stress}

Fysisk aktivitet $\varnothing$ ker følsomheten for insulin i kroppen. Derfor bidrar ofte fysisk aktivitet til at blodsukkeret synker under aktiviteten. Det kreves spesialkompetanse for å gi gode råd om trening ved diabetes type 1. Det er en balansekunst der for lite insulin ved trening kan resultere i stigende blodsukker som gjør det vanskelig å gjennomføre en god $\varnothing \mathrm{kt}$.

Stress og smerter bidrar til utskillelse av stresshormoner. Det kan være betryggende å kjenne til at stresshormoner bidrar til å frigjøre glukose og blodsukkerstigning, slik at man forstår hvorfor glukoseverdiene øker mer enn forventet.

\section{Faste og infiltrater}

Faste kan være aktuelt i forbindelse med ulike undersøkelser. Dersom pasienten har riktig dosering av basalinsulinet, skal det tas som normalt. Pasienter med diabetes type 1 skal svært sjelden unnlate å ta basalinsulinet sitt.

Infiltrater er en bivirkning av å bruke insulin. Vi vet at ved gjentatte insulininjeksjoner i samme område danner det seg arrvev og fettansamlinger, som bidrar til dårlig opptak av insulin. Mange pasienter opplever at det er behagelig å sette insulin i disse «fettputene», men resultatet er uforutsigbar effekt av satte insulindoser. 
Et godt tips er å be pasienten vise hvor og hvordan insulininjeksjonene gjennomføres, og kartlegge om det er god variasjon i stedene der disse settes. Ved å flytte injeksjonssted vil insulindosene ofte ha betydelig bedre og mer forutsigbar effekt.

\section{Hypoglykemi - lavt blodsukker}

Dette er den vanligste akutte komplikasjonen som kan oppstå i forbindelse med diabetes. Hypoglykemi er den viktigste bivirkningen ved bruk av insulin. Såkalt føling er et faresignal som forteller at noe må gjøres øyeblikkelig, slik at tilstanden ikke får utvikle seg til å bli alvorlig (1).

Hypoglykemi er en tilstand der blodglukosenivået er kommet ned i 2,5-3,3 mmol/1. Det er store individuelle variasjoner i hvor følingsterskelen ligger (1). Dette problemet forårsaker mye bekymring hos mennesker som lever med diabetes. Hypoglykemi kan inndeles i lett hypoglykemi, alvorlig hypoglykemi og hypoglykemisk koma.

\section{Symptomer ved hypoglykemi}

Symptomer ved lett til moderat hypoglykemi - ett eller flere av følgende symptomer (1):

- konsentrasjonsvansker

- kaldsvette, svetting

- skjelving, risting

- blekhet

- hjertebank

- sult/tørste

- parestesier i leppe/tunge

- hodepine

- forandringer i oppførsel

- kvalme

Symptomer ved alvorlig hypoglykemi:

- talevansker, afasi

- dobbeltsyn

- forvirring, konfusjon

- sterkt unormal eller voldsom oppførsel, irritabilitet og uro 
Symptomer ved hypoglykemisk koma, insulinsjokk:

- nedsatt bevissthet

- bevisstløshet

- kramper og lammelser

- ufrivillig vannlating

En pasient med lett hypoglykemi vil kunne klare å ivareta seg selv og sørge for å iverksette tiltak på egen hånd. Men av og til klarer ikke pasienten det, og det kan haste med å hjelpe vedkommende til å innta noe sukkerholdig som kan avbryte anfallet.

Er pasienten våken, kan man sørge for at vedkommende får i seg cirka 20 gram raskt nedbrytbare karbohydrater. Pasienten vil merke bedring i løpet av 10 til 15 minutter.

Man kan bruke hypostop, som er dekstrose-gel på tube, som fås kjøpt på apotek, eller man kan la pasienten drikke cirka ett glass juice, sukkerholdig brus eller s $\varnothing t$ saft. Druesukker (7-10 stk. à 2 g), rosiner (20 stk.), honning eller sukkerbiter (6-8 stk.) kan også brukes.

Pasienten skal deretter spise langsomt nedbrytbare karbohydrater, for eksempel brød, for å holde blodglukosenivået normalt. Dersom det lar seg gjøre, er det viktig å måle blodglukosenivået før pasienten inntar karbohydrater, og deretter vente cirka 10 til 15 minutter etter inntaket av raske karbohydrater før neste måling.

\section{«Er pasienten bevisstløs, må man sørge for å tilføre glukose intravenøst.»}

Det er vesentlig at pasienten inntar en passende mengde karbohydrater slik at blodglukosenivået ikke blir for høyt. Det kan også være behov for insulin dersom inntaket blir for høyt.

Er pasienten bevisstløs, må man sørge for å tilføre glukose intravenøst. Som regel er det tilstrekkelig å gi $20 \mathrm{ml} 50$ prosent glukose intravenøst. Det er viktig å huske på at 50 prosent glukose er sterkt vevsirriterende dersom man er uheldig og injiserer ekstravasalt, altså utenfor blodkaret.

Et alternativ er å gi $1 \mathrm{mg}$ glukagon intramuskulært eller subkutant, som også finnes som nesespray. Glukagon kan forårsake kvalme og oppkast, og det er derfor viktig at pasienten legges i stabilt sideleie. Når pasienten har våknet, må det suppleres med langsomme karbohydrater (1). 
Ved gjentatte hypoglykemier er det viktig at pasienten og behandleren fors $\varnothing$ ker å kartlegge hva som kan ha forårsaket den lave blodglukosen, slik at det ikke gjentar seg.

\section{Årsaker til hypoglykemi}

Vanlige årsaker til hypoglykemi (1) er

- at pasienten ikke har redusert insulindosen før større fysisk aktivitet, eller ved $\varnothing \mathrm{kt}$ fysisk aktivitet

- redusert matinntak - vær obs ved høy alder - eller utilstrekkelig karbohydratinnhold i måltider

- at insulindosen ikke er redusert ved vektreduksjon

- for høy insulindosering - nedsatt legemiddelbehov kan for eksempel forekomme etter at pasienter med nyoppdaget diabetes har fått regulert blodglukosen

- stort alkoholinntak - kan også gjelde dagen etter stort alkoholinntak

- selvmedisinering uten tilstrekkelig innsikt

- cøliaki, binyrebarksvikt, hypertyreose

- infiltrater med opphopning av insulin som frisettes ukontrollerbart

Vi må dessuten være oppmerksomme når eldre personer med diabetes legges inn på sykehus med annen og alvorlig sykdom. Kognitiv svikt og endret næringsinntak kan bidra til svingende blodsukker.

\section{«Også personer med velregulert diabetes kan oppleve tilfeller av hypoglykemi.»}

Særlig risiko kan oppstå i forbindelse med innleggelsessituasjoner der pasienten blir liggende lenge og vente i mottaket, ved røntgenundersøkelser og ved innleggelse på avdelingen.

Også personer med velregulert diabetes kan oppleve tilfeller av hypoglykemi. Noen frykter hypoglykemianfall og foretrekker derfor i stedet å ha jevnt høyere blodglukoseverdier, noe som imidlertid frarådes.

Mens helsepersonell frykter høye blodglukoseverdier, frykter personer med diabetes følinger, for da opplever de å miste kontrollen (1). 


\section{Hyperglykemi og syreforgiftning kan utvikles}

Ved manglende insulin kan pasienter utvikle hyperglykemi - høyt blodsukker - og ganske raskt også syreforgiftning, kalt ketoacidose, avhengig av insulinbehandling. Det er særlig ved behandling med insulinpumpe der pasienten kun behandles med hurtigvirkende insulin at det forekommer risiko for at pasienten raskt utvikler syreforgiftning.

Årsaken er at effekten av hurtigvirkende insulin raskt avtar ved manglende tilførsel - tre til fire timer anses som forventet virketid. Ved uteblitt dosering av basalinsulin er det tilsvarende risiko for syreforgiftning.

Symptomer på hyperglykemi:

- Tørste, munntørrhet og hyppig vannlating er de vanligste. Tåkesyn, redusert allmenntilstand og sløvhet kan også være symptomer på høyt blodsukker, særlig dersom det har vedvart over lengre tid.

- Når insulinmangelen er et faktum, blir pasienten i tillegg kvalm, brekker seg, kaster opp og kan føle seg elendig.

- Dersom hyperglykemien får utvikle seg til en syreforgiftning, skal pasienten behandles på sykehus. Hovedprinsippene for behandlingen er væsketilførsel, insulinbehandling og overvåking eller behandling av elektrolyttbalansen (1).

\section{Livet med diabetes er en balansekunst}

Det å leve med diabetes er en kontinuerlig jobb. Det er en balansekunst der det kan virke enkelt å planlegge og vurdere riktig dosering av insulin, men det er det på langt nær ikke. Det er mange hensyn å ta og mye planlegging for den som har sykdommen.

Respekt og ydmykhet for dem som lever med diabetes type 1, er på sin plass. Du kan lære mye ved å høre på de erfaringene personer med diabetes type 1 har. Etter mine 22 år som diabetessykepleier har jeg en viss forståelse for hva pasientgruppen må beherske. Likevel har jeg fortsatt mye mer å lære.

\section{Referanser}

1. Ribu L, Singstad T. Sykepleie til personer med diabetes mellitus. I: Knutstad, red. Utøvelse av klinisk sykepleie. 3. utg. Oslo: Cappelen Damm Akademisk; 2019.

2. Hanås R. Type 1 diabetes hos barn, ungdom og unge voksne. 3. utg. Oslo: Cappelen Damm Akademisk; 2000.

3. Skafjeld A, Graue M. Diabetes, forebygging, oppfølging og behandling. Oslo: Akribe; 2011. 
4. Helsedirektoratet. Diabetes. Oslo: Helsedirektoratet; u.å. Tilgjengelig fra: https://www.helsedirektoratet.no/tema/diabetes (nedlastet 14.12.2021).

5. Moser O, Riddell MC, Eckstein ML, Adolfsson P, Rabasa-Lhoret R, van den Boom L, et al. Glucose management for exercise using continuous glucose monitoring (CGM) and intermittently scanned CGM (isCGM) systems in type 1 diabetes: position statement of the European Association for the Study of Diabetes (EASD) and of the International Society for Pediatric and Adolescent Diabetes (ISPAD) endorsed by JDRF and supported by the American Diabetes Association (ADA). Diabetologia, 2020;63(12):2501-20.

6. Diabetesforbundet. Diabetes type 1. Oslo: Diabetesforbundet; u.å. Tilgjengelig fra: https://www.diabetes.no/diabetes-type-1/ (nedlastet 14.12.2021).

7. Helsenorge. Diabetes type 1. Helsenorge; u.å. Tilgjengelig fra: https://www.helsenorge.no/sykdom/diabetes/diabetes-type-1/ (nedlastet 14.12.2021).

8. Kursbygger. Diabetes, karbohydrater og insulindoser. Tilgjengelig fra: https://kursbygger.ihelse.net/?startcourseid=141\&tracking (nedlastet 14.12.2021).

9. Norsk Selskap for Endokrinologi. Nasjonal veileder i endokrinologi. Behandling av blodsukker i sykehus. Oslo: Norsk Selskap for Endokrinologi; 2021. Tilgjengelig fra: https://www.endokrinologi.no/index.php? action=showtopic\&topic=ameBeKcN / (nedlastet 14.12.2021). 